\title{
Hemodiálisis crónica con sedación en paciente de 17 años con enfermedad mitocondrial
}

Jesús Márquez Benítez, Lourdes Rìcci Valero, Francisco Calderón Lozano, Anselmo Guareño Antunez, Cándida Santos Ugía, $M^{a}$ Concepción Cruz Cánovas, Yolanda Marín Pérez, Lourdes Blanco LLedo, Asunción Espino Corchero

Enfermeros del Servicio de Nefrología. Hospital Infanta Cristina. Badajoz

\section{Introducción}

Las enfermedades mitocondriales no son muy frecuentes y se pueden manifestar a cualquier edad. Su origen es de tipo hereditario ó esporádico ${ }^{1}$.La mitocondria es el único elemento de la célula que tiene ADN propio. Cuando se produce un error congénito por una mutación u otra anomalía en el gen de alguna de estas proteínas, hay defectos en el metabolismo, causando daños a cerebro, corazón, hígado, riñones, músculos, sistema endocrino y respiratorio entre otros, dando síntomas variados como pérdidas del control motor, retardo en el crecimiento, complicaciones respiratorias, visuales, auditivos e insuficiencia renal. No existe tratamiento específico curativo para estos procesos, limitándose a medidas paliativas, generales y farmacológicas para enlentecer el proceso. La insuficiencia renal llega a veces a necesitar de tratamiento sustitutivo ${ }^{2}$.

Las sesiones de hemodiálisis (HD), bajo sedación, se suelen hacer con relativa frecuencia en Reanimaciòn 0 UCI, a pacientes con patologías muy diversas graves, estando monitorizados y con un estricto control médico. ${ }^{3}$ Estas sesiones no suelen presentar incidencias salvo de tipo hemodinámico, a pesar de estar controlados con drogas vasoactivas.

Presentamos el caso de una paciente de 17 años que necesitó sedación para la realización de hemodiálisis crónica.

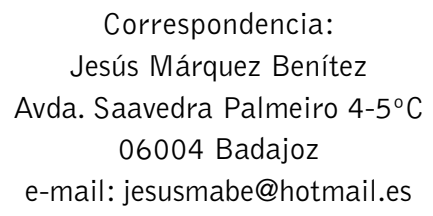

\section{Caso clínico}

Mujer de 17 años de edad, sordomuda, sin reacciones alérgicas conocidas. Como antecedentes personales destacan: Sordera neurosensorial profunda (implante coclear no funcionante desde 2003), Crisis mioclónicas estáticas en tratamiento con Valproato, retraso psicomotor de origen mitocondrial con afectación de la cadena respiratoria 1 y 3, Portadora de mutación en el gen de protrombina, Escoliosis e IRC de etiología túbulointersticial por enfermedad Mitocondrial Congénita en seguimiento hasta entonces por nefrología pediátrica.

Antecedentes Familiares: Un único hermano mayor afectado como ella de Enfermedad Mitocondrial, sordomudo, en diálisis peritoneal durante 4 años, actualmente trasplantado renal de donante cadáver en 2006.

Antecedentes Sociofamiliares: Separación de los padres tras el trasplante del hermano. La madre y abuelos maternos cuidan de los dos. Desde la consulta de nefrología pediátrica se había planteado el trasplante de vivo del padre, estando pendiente de estudio.

La niña antes de la separación estaba bien, mantenía buena relación con los padres y asistía con normalidad a un centro especial educativo donde estaba integrada; pero a raíz de la separación de sus progenitores, sufre cambio brusco en su personalidad, con cambios en el comportamiento y comienza a ser rebelde, con negación de su enfermedad renal y muestras de agresividad y odio hacia su madre.

El día 13-04-2010 la paciente ingresa por cuadro de varias semanas de evolución caracterizado por deterioro del estado general, debilidad, astenia, insomnio, 
imposibilidad para la marcha, mioclonías y movimientos espásticos de los cuatros miembros. Diuresis conservada de 1-2 I/día, no nauseas ni vómitos, destacando en analítica realizada $\mathrm{Cr} 7.2 \mathrm{mg} / \mathrm{dl}, \mathrm{Ca} .11 \mathrm{mg} / \mathrm{l}$, P. $6.8 \mathrm{mg} / \mathrm{l}$.

Durante el ingreso se corrige la hipercalcemia, pero la paciente presenta importante agitación y agresividad, negando cualquier propuesta que se le hace, por lo que es valorado por psiquiatría; TAC de cráneo y ECG normal.

Se decide iniciar tratamiento renal sustitutivo con HD. Para poder implantar catéter femoral en M.I.D se necesita tratamiento neuroléptico sedante (haloperidol ${ }^{\circledR}$ ).

Después de realizar 4 sesiones, se implanta catéter yugular permanente en quirófano bajo sedación, y al haber mejorado la paciente, se decide alta médica con tratamiento sedante pautado por psiquiatra (haloperidol $^{\circledR}$ y benzodiacepinas). Mantenía buen control de parámetros analíticos y de eficacia de HD.

Tras el alta, la paciente manifiesta un comportamiento más agresivo, con intento de autolisis y lesión a familiares, sobre todo cuando se aproxima la hora de acudir a las sesiones de hemodiálisis, teniendo que ser forzada para el traslado en ambulancia, con necesidad incluso de contención durante el viaje. Durante la sesión necesita permanente vigilancia por dos personas y asistencia de la madre a las sesiones porque es la única que puede comunicarse con ella con el lenguaje de signos. Se solicita consulta de nuevo con psiquiatra y psicólogo. En la $8^{a}$ sesión de HD la paciente se arranca el catéter tunelizado, y en las siguientes, llega siempre alterada, dando gritos, negándose a que se la conectara; muestra signos continuos de agresividad, como morder las líneas, levantarse de la cama o agredir al personal que intenta controlarla. Durante la diálisis, la alarma del monitor suena continuamente por falta de flujo al no cesar de moverse. Se solicita a Anestesia sedación y es necesario tratamiento con Midazolam y Propofol 4,5,6 endovenoso, haciéndose 6 sesiones en el servicio de Reanimación con vigilancia del Anestesista. La dificultad de comunicación de nefrólogos y enfermeras con la paciente hacía necesaria la presencia de la madre 0 del padre siempre, (aunque ella prefería a este), con evidente mala relación entre progenitores que interfería en la estabilidad emocional de la enferma.
A pesar de las explicaciones de los padres, la paciente no aceptaba el tratamiento renal sustitutivo incluida la Diálisis Peritoneal y manifestando su deseo de morir. La madre había solicitado la incapacidad por vía judicial.

Se propuso trasplante renal de vivo, en este caso del padre, ya que la madre era la cuidadora de los dos hermanos, pero éste era algo ambiguo en su consentimiento, aunque al final aceptó hacerse las pruebas de compatibilidad, debido a la relevancia y gravedad de la situación. Al mismo tiempo se planteó a la ONT la necesidad de trasplante preferente.

El 18-05-2010 avisan de la ONT que tienen un donante para el trasplante renal. Llega la paciente a nuestra unidad en la misma situación que días anteriores.

Realizadas las pruebas según protocolo, se procede a la intervención quirúrgica para trasplante. Se realiza este sin complicaciones y tras permanecer 24 horas en UCI con sedación sale a la unidad de TX. Renal. Durante su estancia en esta unidad permaneció, rebelde, muy agitada, nerviosa 7 y negándose a tomar la medicación. Se arranca vías venosas y sonda vesical con salida del catéter "doble J", así como el drenaje abdominal.

Es dada de alta el 26 - 05 -2010, acudiendo periódicamente a la consulta de TX.Renal.

Durante las primeras visitas a esta consulta, viene a la fuerza, chillando, agresiva y con falta de colaboración, siendo necesaria la intervención de varias personas, para realizarle las extracciones de sangre, llegando a orinarse en la misma consulta y gritando en todo momento.

\section{Discusión}

Nuestra unidad se vio de alguna manera alterada por este caso, dado que a veces era necesario que varios componentes del equipo estuvieran pendientes de la paciente; el resto de pacientes estaban incómodos con la situación planteada, aunque colaboraban.

Nos encontramos ante una paciente con patología psicológica - psiquiátrica y orgánica debido a su enfermedad de base y con problemas en relaciones familiares. EI 
personal del servicio se volcó con ella de una manera importante, aportándole todo tipo de explicaciones y mostrándole afecto y seguridad.

La relación y el trato del personal con los padres fue exquisito en todo momento, a pesar de que el padre protestaba por todas las decisiones que se tomaban y culpando siempre a la madre, Se palpaba la tensión entre los padres cuando coincidían al lado de la hija. La situación psicológica de la madre pasó por momentos de gran tensión emocional, mantuvo siempre apoyo psicológico y de todo el personal de la unidad.

Actualmente la paciente, está muy bien, alegre, encantadora, colaboradora; comunicativa, e ilusionada por haber vuelto a su colegio y según la madre hace vida normal.

La comunicación entre madre e hija es excelente; pero con el padre no tiene relación alguna actualmente.

Viene a revisiones periódicas en la consulta de Trasplante Renal (Cr. de $0.8 \mathrm{mg} / \mathrm{dl}$ ), acompañada por la madre y hermano, colabora en la extracción de sangre y espera tranquila el tiempo necesario de la consulta. Ha venido a vernos varias veces a nuestra unidad, con su madre y hermano y aunque no ha querido entrar, nos saluda cariñosamente. Según la madre, quiere escribir una carta para darnos las gracias por todo.

\section{Conclusión}

A modo de reflexión sobre este caso queremos destacar la importante labor de enfermería aportando apoyo psicológico a los padres, intentando no crear conflictos entre ellos y manifestando frente la paciente en todo momento un ambiente de cordialidad y seguridad.

¿Qué hacer cuando un paciente joven no acepta tratamiento sustitutivo?

$1^{\circ}$-Valoración por psicólogo, psiquiatra, para confirmación estado mental, y debe ser la familia asesorados por el equipo médico los que tomen una decisión si el paciente no está en condiciones de decidir. Los problemas de relaciones familiares pueden complicar aún más una situación ya difícil y el personal de enfermería debe evitar entrar en este circulo vicioso. $2^{\circ}$ - Debemos garantizar siempre la seguridad del paciente durante la hemodálisis, y evitar agravar los daños que ya padece. ¿Se puede obligar a esta paciente a que asista por la fuerza a un tratamiento como es la hemodiálisis, en el que la colaboración del paciente es fundamental, con riesgo de complicaciones graves? ¿Cuánto tiempo se podría haber aguantado esta situación si no hubiera llegado el TX renal? (Se le realizaron 19 sesiones de HD).

$3^{\circ}$ - En este caso y otros parecidos, todos deberíamos reflexionar y si es posible, antes de llegar a tratamiento sustitutivo, incluirlos en lista de TX, para no llegar a estas situaciones límites.

\section{Bibliografía:}

1. Rubio González T, Verdecia Jarque M. Las enfermedades mitocondriales: un reto para las ciencias médicas [artículo en línea]. MEDISAN 2004;8(1). http://bvs.sld.cu/revistas/san/vol8_1_04/ san08104.htm

2. Szabolcs MJ, Seigle $R$, Shaunske $S$ et al. mitocondrial DNA deletion a cause of chronic tubulointersticial nephropathy. Kidney int. 1994; 45: 1388

3. Tratado de cuidados críticos y emergencias.Luís miguel Torres Morera. Capit. 13 (sedación en las unidades de cuidados críticos).M.Mato pag. $391-43$.

4. MASUI 2004. May, 53 85) 508 - 13. La influencia de la hemodiálisis intermitente y la concentración de propofol en sedación intravenosa postoperatoria Tatebayashi S. Nara ( japon)

5. Enfermería y urgencias (F. del Busto de Prado) 2001. Hipnosis, sedación y analgesia Cap, 9 ( 203-209)

6. Seminarios en diálisis. Volumen $24 n^{\circ} 1$.El riesgo de la sedación/ analgesia en pacientes en hemodiálisis. Procedimientos intervencionistas. Gerald A. Houston febrero 2.011

7. Enfermeria y urgencias ( F. del Busto de Prado ) 2001 .Cap. 10 ( urgencias Psiquiatricas, intervención en crisis y violencia ) 209- 230 